\title{
Internal past, external past, and counterfactuality: evidence from Japanese*
}

\author{
Naoko Komoto \\ University of Washington
}

\begin{abstract}
This paper argues that there are two different types of counterfactuality, which are overtly represented in Japanese by adding the past either to the main verb or to the modal. In one pattern where the modal takes scope over the past, the counterfactuality cannot be canceled. Along the lines of Iatridou's (2000) and Ogihara's (2008) analyses, I propose that the past is a modal past and it directly indicates the counterfactuality. In another pattern where the past takes scope over the modal, the counterfactuality can be canceled. Appealing to the ideas provided in Condoravdi 2002 and Ippolito 2003, 2006, I suggest that the past is temporal and it expresses that there was a past time when the proposition could still be true. The accessibility relation is defined in the past. The counterfactuality is obtained by the conversational implicature.
\end{abstract}

Keywords: past, modal, scope, conditional, counterfactuality

\section{Introduction}

The aim of this paper is to show that there are two different types of counterfactuality, depending on the scope relations of the past and the modal. Let us consider the examples in (1a,b) and (2a,b). In Japanese, two different syntactic surface orders of the past and the modal kamosirena- 'may/might' are possible in a consequent clause of counterfactual conditionals. The patterns are schematically described in (1a) and (2a), while Japanese sentences are given in (1b) and (2b). In the former pattern, the past tense morpheme is attached to the verb and it occurs inside the modal. In the latter pattern, the past is added to the modal and it occurs outside the modal. I refer

* I would like to thank the audiences at the Northwest Linguistics Conference 25 (UBC) and SALT 20 (UBC and SFU) for their valuable comments and suggestions. I am indebted to Toshiyuki Ogihara and Laurel Preston for extensive discussions and feedback. I received helpful input from Hyunjung Ahn, Edith Aldridge, Barbara Citko, Sarah Churng, Atsushi Fujimori, Derek Gulas, Russell Hugo, Kumiko Kato, Hideo Makihara, Dan McCloy, Ayako Moewaki, Osamu Sawada, the members of the UW Semantics Roundtable, and SALT abstract reviewers. Special thanks go to Derek Gulas for the editorial help and Morgan Mamemi for LATEX advising. All remaining errors are my own.

C2011 Naoko Komoto 
Internal past, external past, and counterfactuality

to the former pattern as Internal Past and the latter pattern as External Past. Both patterns produce counterfactual readings: $:^{1,2}$

\section{(1) Internal Past}

a. Antecedent clause (if-clause), ... [verb-PAST] [modal-NONPAST]

b. Go-zi-no hikooki-ni nor-eba, Ken-wa asita Siatoru-ni five o'clock-GEN plane-DAT take-if, Ken-TOP tomorrow Seattle-DAT tui-ta kamosirena-i. arrive-PAST may/might-NONPAST

'If (he) had taken the five o'clock plane, Ken might have arrived in Seattle tomorrow.'

(2) External Past

a. Antecedent clause (if-clause), ... [verb-NONPAST] [modal-PAST]

b. Go-zi-no hikooki-ni nor-eba, Ken-wa asita Siatoru-ni five o' clock-GEN plane-DAT take-if, Ken-TOP tomorrow Seattle-DAT tuk-u kamosirena-katta. arrive-NONPAST may/might-PAST

'If (he) had taken the five o' clock plane, Ken might have arrived in Seattle tomorrow.'

Palmer (1986, 2001) and Iatridou (2000) point out that the past tense morpheme is employed to convey counterfactuality among many languages. Building on their observations, this paper is focused on two different possible combinations of the past and the modal in Japanese counterfactual conditionals. I compare and contrast these two patterns, proposing the semantics of them. Let us note that when the past tense form is not used on the verb or the modal in a consequent clause, the sentence does not express counterfactuality. The schematic form is given in (3a). A Japanese example is provided in (3b). Sentence (3b) does not convey that Ken does not take the five o'clock plane: ${ }^{3}$

1 The present paper defines that counterfactuals are grammatical constructions which convey information contrary to fact. We typically assume something which is not true in the actual world, and then conclude something on the basis of this supposition in a way that is maximally compatible with the evaluation world.

2 A future adverb such as asita 'tomorrow' is incompatible with the pastness of the past tense morpheme, and thus it disambiguates the reading of the sentence. In Internal Past, when the past tense morpheme does not occur with a future adverb, the sentence is ambiguous between a counterfactual reading and an epistemic reading.

3 One more combination pattern is possible, which I refer to as Double Past. The past tense morpheme is attached to both the verb and the modal, as shown in (ia,b). This type shows the properties of both Internal Past and External Past (i.e. the counterfactuality cannot be canceled (like the Internal Past) 
Naoko Komoto

Non-past

a. Antecedent clause (if-clause), ... [verb-NONPAST] [modal-NONPAST]

b. Go-zi-no hikooki-ni nor-eba, Ken-wa asita Siatoru-ni five o'clock-GEN plane-DAT take-if, Ken-TOP tomorrow Seattle-DAT tuk-u kamosirena-i. arrive-NONPAST may/might-NONPAST

'If (he) takes the five o'clock plane, Ken might arrive in Seattle tomorrow.'

The two patterns observed in Japanese are theoretically intriguing in that we obtain a counterfactual reading in two distinct configurations where the modal takes scope over the past and where the past takes scope over the modal. According to the scope relations of the past and the modal, the past contributes to the counterfactuality in a different way. We thus obtain two different types of counterfactuality. I claim that in one pattern where the past occurs inside the modal, the past is a modal past and it directly indicates the counterfactuality. I propose that the actual world is excluded along the lines of Iatridou 2000 and Ogihara 2008. In another pattern where the past arises outside the modal, the past is employed to go back to a past when the proposition could still be true. I appeal to the ideas provided in Condoravdi 2002 and Ippolito 2003, 2006. The counterfactuality is obtained by the conversational implicature in the latter type: the relevant past possibility is no longer available at the utterance time. We therefore infer that the proposition is false.

This paper is organized as follows. Section 2 provides the data to illustrate that two different syntactic surface orders of the past and the modal represent two different types of counterfactuality. Section 3 gives the descriptive and theoretical backgrounds of this study. Section 3.1 makes explicit the reason the present paper is focused on the scope relations of the past and the modal in a consequent clause. Section 3.2 provides an overview of previous analyses which discuss the semantic contribution of the past tense morpheme in counterfactual contexts. Section 4 proposes the semantics of the two different types, employing the ideas suggested in the previous analyses. Section 5 concludes this paper.

but the proposition is evaluated in the past (like the External Past)):

(i) Double Past

a. Antecedent clause (if-clause), ... [verb-PAST] [modal-PAST]

b. Go-zi-no hikooki-ni nor-eba, Ken-wa asita Siatoru-ni tui-ta five o'clock-GEN plane-DAT take-if, Ken-TOP tomorrow Seattle-DAT arrive-PAST kamosirena-katta. may/might-PAST

'If (he) had taken the five o'clock plane, Ken might have arrived in Seattle tomorrow.' 
Internal past, external past, and counterfactuality

\section{Two types of counterfactuals}

In this section, I will show that (i) both patterns convey counterfactuality and that (ii) the counterfactuality of Internal Past cannot be canceled, while the counterfactuality of External Past can be canceled. To be more concrete, I will observe that Internal Past (IP) is used under Scenarios 2 and 4, while External Past (EP) is employed under Scenarios 2, 4, and 5:

$\begin{array}{lcc}\text { Scenarios } & \text { IP } & \text { EP } \\ \text { 1: The truth (or the falsity) of the antecedent is not determined. } & \# \text { \# } \\ \text { 2: The antecedent will not be true. } & \text { ok ok } \\ \text { 3: The antecedent will be true. } & \# \text { \# } \\ \text { 4: The antecedent was not true. } & \text { ok ok } \\ \text { 5: The antecedent was true. } & \# \text { ok }\end{array}$

\subsection{Data}

Let us assume the situation in (5) and consider Internal Past and External Past counterfactual conditionals under Scenarios 1 through 5, which will be provided one by one:

(5) Situation: Ken is participating in a chess tournament. His next game is scheduled to take place the following Wednesday. Ken's opponent has not been determined yet, but Paul is a better player than Ken is. On Monday, Ken's friend Mary thinks that if Paul is Ken's opponent, Ken might lose Wednesday's game.

First, let us examine the data, which suggests that when the truth (or the falsity) of the antecedent is not determined, both patterns are anomalous. Under Scenario 1 in (6), Ken's opponent is not determined yet. Thus Paul will be Ken's opponent or Paul will not be Ken's opponent in the game. The possibility that Paul is Ken's opponent and Ken loses Wednesday's game in the future is arguably available in the past (e.g., On Monday, Mary thinks that if Paul is Ken's opponent, Ken might lose Wednesday's game). Neither Internal Past nor External Past is possible under this scenario, as shown in (6a) and (6b). One way to report the past possibility is to employ a periphrastic verb omou 'think', as in (6c):

(6) [Scenario 1] Tuesday: Ken's opponent has not been determined yet (i.e. Paul will be or will not be Ken's opponent in the game).

a. Internal Past

\#Pooru-ga aite nara, Ken-wa suiyoobi-no siai-de

Paul-NOM opponent if Ken-TOP Wednesday-GEN game-DAT 
make-ta kamosirena-i.

lose-PAST may/might-NONPAST

'If Paul had been (his) opponent, Ken might have lost Wednesday's game.'

b. External Past

\#Pooru-ga aite nara, Ken-wa suiyoobi-no siai-de

Paul-NOM opponent if Ken-TOP Wednesday-GEN game-DAT

maker-u kamosirena-katta.

lose-NONPAST may/might-PAST

'If Paul had been (his) opponent, Ken might have lost Wednesday's game.'

c. Pooru-ga aite nara, Ken-wa suiyoobi-no siai-de

Paul-NOM opponent if Ken-TOP Wednesday-GEN game-DAT

maker-u kamosirena-i to kinoo omot-ta.

lose-NONPAST may/might-NONPAST comp yesterday think-PAST

'Yesterday (I) thought that if Paul is (his) opponent, Ken might lose Wednesday's game.'

The following contrast between the examples in Scenario 2 and Scenario 3 suggests that Internal Past and External Past convey that the antecedent proposition is counterfactual. First, let us assume Scenario 2, where Paul will not participate in the game. The antecedent is false about the future in this scenario and both Internal Past and External Past are possible:

(7) [Scenario 2] Tuesday: Mary hears that Paul decided not to participate in the tournament (i.e. Paul will not be Ken's opponent in the game).

a. Internal Past $(=(6 a))$

Pooru-ga aite nara, Ken-wa suiyoobi-no siai-de

Paul-NOM opponent if Ken-TOP Wednesday-GEN game-DAT

make-ta kamosirena-i.

lose-PAST may/might-NONPAST

'If Paul had been (his) opponent, Ken might have lost Wednesday's game.'

b. External Past $(=(6 b))$

Pooru-ga aite nara, Ken-wa suiyoobi-no siai-de

Paul-NOM opponent if Ken-TOP Wednesday-GEN game-DAT

maker-u kamosirena-katta.

lose-NONPAST may/might-PAST

'If Paul had been (his) opponent, Ken might have lost Wednesday's game.' 
Internal past, external past, and counterfactuality

Under Scenario 3 in (8), on the other hand, Paul will be Ken's opponent in the game. In this scenario, where the truth of the antecedent is confirmed, neither Internal Past nor External Past is possible:

(8) [Scenario 3] Tuesday: Mary hears that Paul will be Ken's opponent in the game.

a. Internal Past $(=(6 a))$

\#Pooru-ga aite nara, Ken-wa suiyoobi-no siai-de

Paul-NOM opponent if Ken-TOP Wednesday-GEN game-DAT maker-u kamosirena-katta.

lose-NONPAST may/might-PAST

'If Paul had been (his) opponent, Ken might have lost Wednesday's game.'

b. External Past $(=(6 b))$

\#Pooru-ga aite nara, Ken-wa suiyoobi-no siai-de

Paul-NOM opponent if Ken-TOP Wednesday-GEN game-DAT maker-u kamosirena-katta.

lose-NONPAST may/might-PAST

'If Paul had been (his) opponent, Ken might have lost Wednesday's game.'

Both Internal Past and External Past are possible in Scenario 2, but impossible in Scenario 3. This suggests that both patterns convey counterfactuality.

Let us next examine the scenarios concerning Wednesday after the game. Under Scenario 4 in (9), Paul was not Ken's opponent in the game. Both Internal Past and External Past can be used in this scenario, which suggests that both patterns convey that the antecedent is counterfactual:

(9) [Scenario 4] Wednesday after the game: Paul was not Ken's opponent and Mary knows that.

a. Internal Past

Pooru-ga aite nara, Ken-wa kyoo-no siai-de make-ta Paul-NOM opponent if Ken-TOP today-GEN game-DAT lose-PAST

kamosirena-i.

may/might-NONPAST

'If Paul had been (his) opponent, Ken might have lost today's game.'

b. External Past

Pooru-ga aite nara, Ken-wa kyoo-no siai-de

Paul-NOM opponent if Ken-TOP today-GEN game-DAT

maker-u kamosirena-katta.

lose-NONPAST may/might-PAST 
'If Paul had been (his) opponent, Ken might have lost today's game.'

Under Scenario 5 in (10), on the other hand, Paul was Ken's opponent in the game. Both Internal Past and External Past convey that Paul was not Ken's opponent and thus both patterns are anomalous in this scenario:

(10) [Scenario 5] Wednesday after the game: Paul was Ken's opponent and Mary knows that.

a. Internal Past (= (9a))

\#Pooru-ga aite nara, Ken-wa kyoo-no siai-de make-ta

Paul-NOM opponent if Ken-TOP today-GEN game-DAT lose-PAST

kamosirena-i.

may/might-NONPAST

'If Paul had been (his) opponent, Ken might have lost today's game.'

b. External Past $(=(9 b))$

\#Pooru-ga aite nara, Ken-wa kyoo-no siai-de
Paul-NOM opponent if Ken-TOP today-GEN game-DAT
maker-u kamosirena-katta.
lose-NONPAST may/might-PAST
'If Paul had been (his) opponent, Ken might have lost today's game.'

When we provide additional information, however, the counterfactuality of External Past can be canceled, as in (11b). The counterfactuality of Internal Past, on the other hand, cannot be canceled, as in (11a):

(11) [Scenario 5] (see above)

a. Internal Past

\#(9a) ... Sorede kaeri-no sitaku-o si-tei-ta. Zissai

(9a) ... So return-GEN packing-ACC do-PROG-PAST actually

Pooru-ga aite dat-ta.

Paul-NOM opponent COPULA-PAST

'If Paul had been (his) opponent, Ken might have lost today's game. So (I) was packing for (our) return. Paul was actually (his) opponent.'

b. External Past

(9b) ... Sorede kaeri-no sitaku-o si-tei-ta. Zissai

(9b) ... So return-GEN packing-ACC do-PROG-PAST actually

Pooru-ga aite dat-ta.

Paul-NOM opponent COPULA-PAST 
Internal past, external past, and counterfactuality

'If Paul had been (his) opponent, Ken might have lost today's game. So (I) was packing for (our) return. Paul was actually (his) opponent.'

The above data suggest that External Past can be used in a situation where the antecedent was true in the past, while Internal Past cannot be employed under the same situation. Let us note that under Scenarios 1 and 3, External Past cannot be used even when the same information is provided. Consider the examples in (12) and (13). When the truth (or the falsity) of the antecedent is not determined (Scenario 1), or when the antecedent will be true (Scenario 3), the counterfactuality of External Past cannot be canceled:

(12) [Scenario 1] Tuesday: Ken's opponent is not determined yet (i.e. Paul will be or will not be Ken's opponent in the game).
\#Pooru-ga aite nara, Ken-wa kyoo-no siai-de maker-u Paul-NOM opponent if Ken-TOP today-GEN game-DAT lose-NONPAST kamosirena-katta. Sorede kaeri-no sitaku-o si-tei-ta. may/might-PAST So return-GEN packing-ACC do-PROG-PAST
Zissai Pooru-ga aite dat-ta kadooka actually Paul-NOM opponent COPULA-PAST whether wakar-ana-i keredomo. know-NEG-NONPAST though

'If Paul had been (his) opponent, Ken might have lost Wednesday's game. So (I) was packing for (our) return. I do not know whether or not Paul was actually (his) opponent, though.'

(13) [Scenario 3] Tuesday: Mary hears that Paul will be Ken's opponent in the game.
\#Pooru-ga aite nara, Ken-wa suiyoobi-no siai-de
Paul-NOM opponent if Ken-TOP Wednesday-GEN game-DAT
maker-u kamosirena-katta. Sorede kaeri-no sitaku-o lose-NONPAST may/might-PAST So return-GEN packing-ACC
si-tei-ta. Zissai Pooru-ga aite dat-ta.
do-PROG-PAST actually Paul-NOM opponent COPULA-PAST

'If Paul had been (his) opponent, Ken might have lost today's game. So (I) was packing for (our) return. Paul was actually (his) opponent.'

\subsection{Summary}

The observations are summarized in (14). Both Internal Past (IP) and External Past (EP) are used in Scenarios 2 and 4. When some appropriate context is provided, 
External Past can also be employed in Scenario 5:

$\begin{array}{lcc}\text { Scenarios } & \text { IP } & \text { EP } \\ \text { 1: It is not determined whether Paul will be Ken's opponent. } & \# & \# \\ \text { 2: Paul will not be Ken's opponent. } & \text { ok } & \text { ok } \\ \text { 3: Paul will be Ken's opponent. } & \# & \# \\ \text { 4: Paul was not Ken's opponent. } & \text { ok } & \text { ok } \\ \text { 5: Paul was Ken's opponent. } & \# & \text { ok }\end{array}$

The above data illustrates that both Internal Past and External Past convey counterfactuality, while they are different in terms of cancelability. If some appropriate information is provided, the counterfactuality of External Past can be canceled. The External Past can be employed when the antecedent proposition was true in the past (as observed in (11b) under Scenario 5). ${ }^{4}$

\section{Previous analyses}

This section provides the descriptive and theoretical backgrounds of the present study. In section 3.1, I make explicit the reason that this paper is focused on the scope relations of the past and the modal in a consequent clause. Section 3.2 gives an overview of two different views for the semantic contribution of the past tense morpheme in counterfactual contexts.

\subsection{Empirical background}

\subsubsection{Past in counterfactual contexts}

Palmer (1986, 2001) and Iatridou (2000) observe that the past tense morpheme is employed to convey counterfactuality among a number of unrelated languages. It suggests that it is not an accident that a past tense morpheme is employed to express counterfactuality. Building on their observations, the present paper is focused on the combinatory possibilities of the past and the modal.

The semantic contribution of the past tense morpheme is one of the most intriguing puzzles in counterfactual conditionals. This peculiar aspect is evident when counterfactual conditionals involve the future. Let us examine the sentences in $(15 a, b)$ and $(16 a, b)$. The past tense morpheme usually does not co-occur with a future adverb as in $(15 \mathrm{a}, \mathrm{b})$, while it can occur with a future adverb in counterfactual conditionals, as shown in $(16 \mathrm{a}, \mathrm{b})$. It seems that the past tense morpheme does not

4 The main goal of this paper is to propose that there are two different types of counterfactuality, depending on the syntactic surface orders of the past and the modal. The present paper leaves the detailed investigation concerning the asymmetry between future and past for future research. 
Internal past, external past, and counterfactuality

express the pastness of the event which the predicate dictates. In section 3.2, I will provide an overview of the previous analyses which discuss the semantic contribution of the past tense morpheme in counterfactual contexts:

a. ${ }^{*}$ John left tomorrow.

b. *John had left tomorrow.

(16) a. If John left tomorrow, he would get there next week.

b. If John had left tomorrow, he would have had a more pleasant journey.

\subsubsection{Past in a consequent clause}

This paper is focused on the scope relations of the past and the modal in a consequent clause. This builds on Ogihara's (2008) study, which claims that the past tense in a consequent clause induces a counterfactual meaning in Japanese. Let us consider the examples in $(17 a, b)$. Example (17a) is an epistemic conditional, which conveys the speaker's uncertainty about whether the antecedent proposition is true or not. Ogihara (2008) maintains that regardless of the particular indicator of a conditional or the tense used in the antecedent clause, the sentence does not convey a counterfactual meaning. We can observe that the non-past tense form of the verb occurs in the consequent clause in (17a). ${ }^{5}$ Sentence (17b), on the other hand, is a counterfactual conditional. It conveys that the antecedent is false - Ken did not take the five o'clock plane. ${ }^{6}$ We can observe that when the past tense form of the verb is employed in the consequent clause, the sentence expresses a counterfactual meaning. The contrast between (17a) and (17b) suggests that the counterfactuality of the sentence is due to the presence of the past tense morpheme in a consequent clause:
a. Go-zi-no hikooki-ni
five o'clock-GEN plane-DAT
nor-eba/not-ta-ra/nor-u-nara/not-ta-nara, Ken-wa asita take-if/take-PAST-if/take-NONPAST-if/take-PAST-if, Ken-TOP tomorrow Siatoru-ni tuk-u daroo.
Seattle-DAT arrive-NONPAST would
'If (he) takes the five o'clock plane, Ken would arrive in Seattle tomorrow.'
b. Go-zi-no
hikooki-ni
five o'clock-GEN plane-DAT

5 I leave the detailed investigation about the semantic contribution of the tense morpheme in the antecedent clause in counterfactual contexts for future research.

6 Sentence (17b) can also convey that Ken does not take the five o'clock plane or that Ken will not take the five o'clock plane. It depends on the context where this sentence is employed. 
Naoko Komoto

nor-eba/not-ta-ra/nor-u-nara/not-ta-nara, $\quad$ Ken-wa asita take-if/take-PAST-if/take-NONPAST-if/take-PAST-if, Ken-TOP tomorrow

Siatoru-ni tui-ta daroo.

Seattle-DAT arrive-PAST would

'If (he) had taken the five o'clock plane, Ken would have arrived in Seattle tomorrow.'

\subsection{Theoretical background: two different views}

For the semantic contribution of the past tense morpheme in counterfactual contexts, Iatridou (2000) provides one way to capture the intuition concerning the relationship between the past tense morpheme and counterfactuality. The main idea is that the past tense morpheme has an exclusion feature. Iatridou (2000) proposes that the semantics of the past tense morpheme is defined as shown in (18):

(18) $\mathrm{T}(x)$ excludes $\mathrm{C}(x)$, where the variable $x$ ranges over time and world. [Note: $\mathrm{T}(x)$ stands for "Topic $(x)$ " (i.e. "the $x$ that we are talking about"). $\mathrm{C}(x)$ stands for "Context $(x)$ " (i.e. "the $x$ that for all we know is the $x$ of the speaker").]

Iatridou (2000) argues that in the temporal domain, the topic time excludes the context time (i.e. the utterance time). Thus the past tense morpheme conveys pastness. ${ }^{7}$ In the modal domain, on the other hand, the topic worlds exclude the context worlds (i.e. the actual world or epistemically accessible worlds). Thus the past tense morpheme conveys counterfactuality.

Condoravdi (2002) and Ippolito $(2003,2006)$ provide a different view on the semantic contribution of the past tense morpheme. ${ }^{8}$ Referring to Thomason (1984), they argue that the past tense morpheme is employed to go back to a past when the proposition could still be true. They implement this by proposing that the past tense takes scope over the modal and that the time argument of the accessibility is defined in the past. The counterfactuality is obtained by the conversational implicature: the relevant past possibility is no longer available at the utterance time.

7 As Ogihara (2008: 14) and von Fintel (2009: 23) independently note, we need additional discussion about why the past tense morpheme expresses past rather than past or future, when we assume that the past tense morpheme is employed to exclude the context time (i.e. the present time). One possibility raised in Iatridou (2000: 246) is that "future" is modal and tense is only past or present.

8 To be more precise, Ippolito (2006) proposes different semantics from Ippolito (2003) for counterfactual conditionals. Ippolito (2006) also suggests an additional different view on the semantic contribution of the past in two-past counterfactual conditionals such as (i).

(i) If Charlie had taken his Advanced Italian test tomorrow, he would have passed.

The reader is referred to Ippolito 2006 for the detailed analysis. Also see note 10. 
Internal past, external past, and counterfactuality

To be more concrete, Condoravdi (2002) argues that sentence (19a) has a counterfactual reading and that the tense and the modal have the scope relation described in (19b). Representation (19b) suggests that "he might have won" is true when the clause "he might win" is true in the past. $M B$ stands for the modal base, which restricts the domain of quantification for might. In Condoravdi's (2002) analysis, the modal might involves metaphysical modality in the counterfactual reading. ${ }^{9}$ The perfect and the modal are translated in (19c) and (19d) respectively, in terms of AT relation. AT relation is defined in $(19 \mathrm{e})$. AT $(t, w, P)$ means that property $P$ is instantiated in world $w$ at time $t$. $\left[t,{ }_{-}\right)$stands for an interval running from the initial subinterval $t$ to positive infinity:

(19) a. He might have won the game.

b. PRES (PERF (MIGHT ${ }_{M B}$ (he win the game)))

c. $\llbracket \mathrm{PERF} \rrbracket=\lambda P \lambda w \lambda t \exists t^{\prime}\left[t^{\prime} \prec t \& \operatorname{AT}\left(t^{\prime}, w, P\right)\right]$

d. $\llbracket$ MAY/MIGHT $M B \rrbracket=\lambda P \lambda w \lambda t \exists w^{\prime}\left[w^{\prime} \in M B(w, t) \& \operatorname{AT}\left(\left[t,{ }_{-}\right), w^{\prime}, P\right)\right]$

e. $\operatorname{AT}(t, w, P)=($ i) $\exists e[P(w)(e) \& \tau(e, w) \subseteq t]$ if $P$ is eventive, (ii) $\exists e[P(w)(e)$ $\& \tau(e, w) \circ t$ ] if $P$ is stative, (iii) $P(w)(t)$ if $P$ is temporal. [If $P$ is a property of eventualities, $P$ is instantiated in $w$ at $t$ iff there is an eventuality $e$ such that $P$ is true of $e$ in $w$ and the temporal trace of $e$ in $w$ is located with respect to $t$ in a certain way. The event is included within the time, while the state overlaps the time. If $P$ is a property of times, $P$ is instantiated in $w$ at $t$ iff $P$ is true of $t$ in $w$.]

Based on these, Condoravdi (2002) states that the counterfactual reading of sentence (19a) is translated into (20). The translation (20) states that there is a time $t^{\prime}$ such that $t^{\prime}$ precedes the utterance time, and there is a world $w^{\prime}$ which is a metaphysical alternative to the world $w$ at $t^{\prime}$, and there is an event $e$, where he wins the game in $w^{\prime}$, and its temporal trace $\tau\left(e, w^{\prime}\right)$ is a subinterval of $\left[t^{\prime},_{-}\right)$:

$$
\begin{aligned}
& \lambda w \exists w^{\prime} \exists t^{\prime}\left[t ^ { \prime } \prec \text { now \& } w ^ { \prime } \in M B ( w , t ^ { \prime } ) \& \exists e \left[[\text { he win the game }]\left(w^{\prime}\right)(e) \&\right.\right. \\
& \left.\left.\tau\left(e, w^{\prime}\right) \subseteq\left[t^{\prime},{ }_{-}\right)\right]\right]
\end{aligned}
$$

Condoravdi (2002) suggests that the counterfactual meaning is obtained as in (21). A common ground is defined to be the union of equivalence classes of worlds, which is represented by $\simeq$. The symbol $t_{0}$ indicates the utterance time. As (21) exemplifies, sentence (19a) conveys that it is no longer possible for him to win the game:

(21) a. For any world $w$ in the common ground, and any time $t \prec t_{0}$, the set of historical alternatives of $w$ at $t_{0}$ (i.e. $\left\{w^{\prime} \mid w \simeq t_{0} w^{\prime}\right\}$ ) is a subset of historical alternatives of $w$ at $t$ (i.e. $\left\{w^{\prime} \mid w \simeq{ }_{t} w^{\prime}\right\}$ ), given the monotonicity of $\simeq$.

9 A metaphysical alternative to $w_{0}$ at $t$ is a world $w$ which is the same as $w_{0}$ up to (and including) $t$. 
b. A world in $\left\{w^{\prime} \mid w \simeq w^{\prime}\right\}$ which is not included in $\left\{w^{\prime} \mid w \simeq t_{0} w^{\prime}\right\}$ is outside the common ground.

c. By using an expression that widens the domain of quantification for the modal so that it is partly outside the common ground, the speaker indicates that the relevant state of affairs could not be verified in the common ground. In recovering the speaker's intention, the hearer can reason as follows: ... the speaker must intend to communicate that this past possibility was an unactualized one.

(see Condoravdi 2002: 85,86)

\section{Proposal}

I propose the semantics of Internal Past and External Past, appealing to the ideas provided in the previous analyses. Section 4.1 submits the proposal descriptions, after I observe another difference between Internal Past and External Past. Section 4.2 gives the semantics for each of them.

\subsection{Proposal descriptions}

As observed in section 2, the counterfactuality of Internal Past cannot be canceled, while the counterfactuality of External Past can be canceled. Further Condoravdi (2002) and Ippolito $(2003,2006)$ allow us to observe the examples in (22a) and (22b) with temporal adverbs. The data suggests that External Past is evaluated in the past, in contrast to Internal Past. Internal Past counterfactuals do not co-occur with a temporal adverb as in (22a), while External Past counterfactuals occur with a past adverbial as in (22b):

(22) a. Internal Past

$\{*$ Kinoo-no ziten-de/*asita-no ziten-de $\}, \quad$ Pooru-ga aite \{yesterday-GEN point-at/tomorrow-GEN point-at $\}$ Paul-NOM opponent

nara, Ken-wa asatte-no siai-de make-ta

if Ken-TOP the day after tomorrow-GEN game-DAT lose-PAST

kamosirena-i.

may/might-NONPAST

'As of $\{$ yesterday/tomorrow $\}$, if Paul had been (his) opponent, Ken might have lost the game the day after tomorrow.' 
Internal past, external past, and counterfactuality

\section{b. External Past}

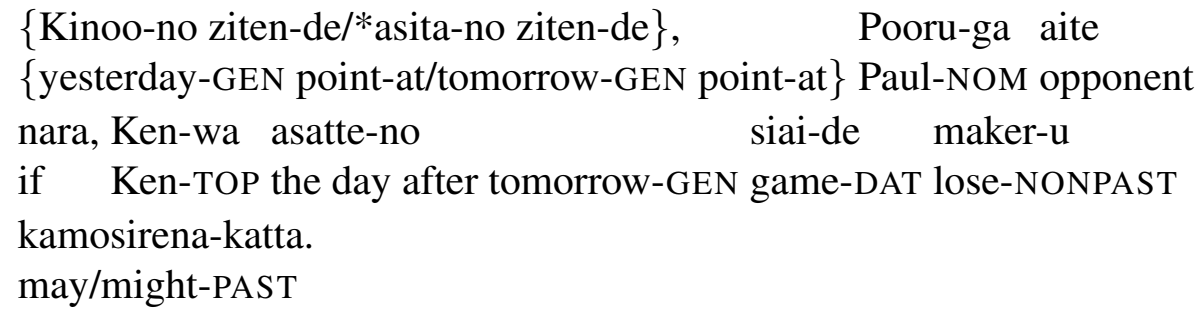

'As of $\{$ yesterday/tomorrow $\}$, if Paul had been (his) opponent, Ken might have lost the game the day after tomorrow.'

From the observations concerning the counterfactuality and the occurrence with temporal adverbs, I submit the proposal in (23). The semantics of Internal Past is proposed along the lines of Iatridou 2000 and Ogihara 2008. For the semantics of External Past, the present paper appeals to the idea provided in Condoravdi 2002 and Ippolito 2003, 2006: ${ }^{10}$

(23) In the Internal Past, the past is a modal past and it directly indicates the counterfactuality. The exclusion feature of the past tense morpheme is employed to exclude the actual world. In the External Past, on the other hand, the past is temporal and it expresses that there was a past time when the proposition could still be true. The accessibility relation is defined in the past. The counterfactuality is obtained by the conversational implicature.

Let us note that Iatridou (2000) argues that when the context worlds are excluded, the sentence does not necessarily refer to the situation contrary to fact in English. An Anderson (1951)-type subjunctive conditional as in (24), for example, conveys that the antecedent is true:

(24) If Jones had taken arsenic, he would have shown just exactly those symptoms which he does in fact show.

10 Ippolito (2006) observes that the antecedent must be interpreted to be counterfactual in two-past subjunctive conditionals such as (i), and proposes that "the past tense carries the counterfactual presupposition that the antecedent got foreclosed at a salient past time and therefore, is no longer historically accessible at the speech time (Ippolito 2006: 667)." To be more concrete, Ippolito (2006) suggests that the past tense denotes "a past time immediately before the time when the possibility expressed by the antecedent got foreclosed" (Ippolito 2006: 651):

(i) If John had run the Boston marathon next spring, he would have finally won.

The present paper does not pursue the possibility that the past moves up to a higher position and the past takes scope over the modal in the Japanese Internal Past. Thus Ippolito's (2006) idea concerning the semantics of the past in two-past subjunctive conditionals is not adopted here to explain the semantics of the Japanese Internal Past. 
Iatridou (2000: 268) further mentions a possibility that in contrast to English, the counterfactuality cannot be canceled in some languages or in some constructions in other languages. As suggested by Ogihara (2008), it seems that when the exclusion feature of the Japanese past tense morpheme is used to exclude the context worlds, we obtain the non-cancelable counterfactuality. An Anderson-type subjunctive conditional is anomalous in Japanese. ${ }^{11}$ Although the judgments about the cancelability for an Anderson-type subjunctive conditional vary according to the speaker in Japanese, what it is important here is that the counterfactuality of the Internal Past is consistent, while the counterfactuality of the External Past is sensitive to the context.

\subsection{The semantics of two types}

The present paper paraphrases Iatridou's (2000) terms as in (25a-d), following Ogihara's (2008) analysis. Context Time and Context World are the time and world for any context $c$ respectively. Topic Time (or reference time) is an interval which satisfies some description $P_{t}$ (e.g. Sunday) under discussion in an arbitrary context $c$, as stated in (25c). The set of Topic Worlds are a subset of those worlds that are "under discussion" in a given context $c$ among those in which the antecedent is true, as in (25d):

a. Context Time: Let $c_{\text {time }}$ stand for the context time for any context $c$.

b. Context World: Let $c_{\text {world }}$ stand for the context world for any context $c$.

c. Topic Time: $\operatorname{Topic}\left(T, P_{t}, c\right)=$ a dense subset $I$ of $T$ (the set of instants) such that $P_{t}(I)=1$ and $I$ is under discussion in the context $c . P_{t}$ indicates a contextually given property of times.

11 A Japanese Anderson-type subjunctive conditional is given in (i). The past tense in the consequent indicates the counterfactuality in the antecedent in (i). Thus it is not compatible with the conclusion that this person drank too much:

(i)??Mosi kono-hito-ga biiru-o nomisugi-ta nara, ima masani kono-hito-ga if this-person-NOM beer-ACC drink too much-PAST if, now exactly this-person-NOM mise-tei-ru shoozyoo-o mise-ta kamosirena-i. Dakara show-PROG-NONPAST symptoms-ACC show-PAST may/might-NONPAST. Therefore

kono-hito-wa biiru-o nomisugi-ta no da. this-person-TOP beer-ACC drink too much-PAST NOMINALIZER COPULA.

'If this person had drunk too much, she might have shown just exactly those symptoms which she shows. I conclude, therefore, that this person drank beer too much.' 
Internal past, external past, and counterfactuality

d. Topic World: Topic $(W, p, c)=$ a subset $W_{1}$ of $W$ (the set of all worlds) such that $W_{1} \subseteq p$ and $W_{1}$ is under discussion in $c$. Here, $p$ represents the proposition supplied by the antecedent of the conditional in question.

(Ogihara 2008: 22)

I assume that the past in the consequent clause takes scope over the antecedent. An example of the Internal Past is provided in (26a) and the semantics is proposed in (26b), along the lines of Iatridou 2000 and Ogihara 2008. Following Ogihara's (2008) analysis, Lewis's (1973) idea of similarity is employed to characterize Topic Worlds as the worlds which are closest to the actual world among those worlds where the antecedent is true:

(26) Internal Past

a. Pooru-ga aite nara, Ken-wa kyoo-no siai-de make-ta Paul-NOM opponent if Ken-TOP today-GEN game-DAT lose-PAST kamosirena-i. may/might-NONPAST

'If Paul had been (his) opponent, Ken might have lost today's game.'

b. In (26a), the exclusion feature of the past tense morpheme is used to exclude the actual world. The presupposition is $c_{\text {world }} \notin \operatorname{Topic}(W, p, c)$, where Topic $(W, p, c)$ is characterized as $\left\{w_{1} \mid\right.$ Paul is Ken's opponent in $w_{1}$ and $\left\{w_{2} \mid\right.$ Paul is Ken's opponent in $\left.w_{2}\right\} \cap\left\{w_{3} \mid w_{3}\right.$ is more similar to $c_{\text {world }}$ than $w_{1}$ is to $\left.\left.c_{\text {world }}\right\}=\emptyset\right\}$. If this presupposition requirement is satisfied, $\llbracket$ sentence $(26 a) \rrbracket^{c_{\text {world }}, c_{\text {time }}}=1$ iff Topic $(W, p, c) \cap\left\{w_{4} \mid\right.$ Ken loses today's game in $\left.w_{4}\right\} \neq \emptyset$.

An example of the External Past is given in (27a). The semantics is described in (27b), employing the ideas provided in Condoravdi 2002 and Ippolito 2003, 2006. The counterfactuality is obtained by the conversational implicature as shown in (21). The past possibility is no longer available at the utterance time. We thus infer that the antecedent proposition is false:

(27) External Past

a. Pooru-ga aite nara, Ken-wa kyoo-no siai-de

Paul-NOM opponent if Ken-TOP today-GEN game-DAT

maker-u kamosirena-katta.

lose-NONPAST may/might-PAST

'If Paul had been (his) opponent, Ken might have lost today's game.' 
b. In (27a), the exclusion feature of the past tense morpheme is employed to exclude the utterance time. The accessibility relation is defined in the past. $\llbracket$ sentence $(27 \mathrm{a}) \rrbracket^{c_{\text {world }}, c_{\text {time }}}=\left\{w_{1} \mid w_{1}\right.$ has the same history as $c_{\text {world }}$ up to Topic $\left(T, P_{t}, c\right)$ and Paul is Ken's opponent in $w_{1}$ at $t_{1}$, where Topic $\left(T, P_{t}\right.$, $c)<t_{1}$ and $\left\{w_{2} \mid w_{2}\right.$ has the same history as $c_{\text {world }}$ up to Topic $\left(T, P_{t}, c\right)$ and Paul is Ken's opponent in $w_{2}$ at $t_{2}$, where Topic $\left.\left(T, P_{t}, c\right)<t_{2}\right\} \cap\left\{w_{3}\right.$ $\mid w_{3}$ is more similar to $c_{\text {world }}$ than $w_{1}$ is to $\left.\left.c_{\text {world }}\right\}=\emptyset\right\} \cap\left\{w_{4} \mid\right.$ Ken loses today's game in $\left.w_{4}\right\} \neq \emptyset$, where $\operatorname{Topic}\left(T, P_{t}, c\right)<c_{\text {time }}$.

\section{Conclusion}

This paper has maintained that there are two different types of counterfactuality, focusing on the semantic contribution of the past tense morpheme. I refer to the pattern where the past occurs inside the modal as Internal Past and the pattern where the past occurs outside the modal as External Past. In the Internal Past, I propose that the past is a modal past and it directly signals the counterfactuality, following Iatridou (2000) and Ogihara (2008). The exclusion feature of the past tense morpheme is employed to exclude the actual world. The External Past, on the other hand, expresses that there was a past time when the proposition could still be true. Appealing to the ideas provided in Condoravdi 2002 and Ippolito 2003, 2006, I claim that the past is temporal and the time argument of the accessibility relation is defined in the past. The counterfactuality is obtained by the conversational implicature: the relevant past possibility is no longer available at the utterance time. We thus infer that the proposition is false. When some appropriate information is provided, the counterfactuality can be canceled. The occurrence with a past temporal adverb suggests that the External Past is evaluated in the past, in contrast to the Internal Past. I propose the semantics of these two types.

\section{References}

Anderson, Alan Ross. 1951. A note on subjunctive and counterfactual conditionals. Analysis 12(2). 35-38.

Condoravdi, Cleo. 2002. Temporal interpretation of modals: Modals for the present and for the past. In David Beaver, Luis Casillas, Brady Clark \& Stefan Kaufmann (eds.), The construction of meaning, 59-87. Stanford: CSLI Publications.

von Fintel, Kai. 2009. Conditionals. Ms. MIT.

Iatridou, Sabine. 2000. The grammatical ingredients of counterfactuality. Linguistic Inquiry 31(2). 231-270. doi:10.1162/002438900554352.

Ippolito, Michela. 2003. Presuppositions and implicatures in counterfactuals. Natural Language Semantics 11(2). 145-186. doi:10.1023/A:1024411924818. 
Internal past, external past, and counterfactuality

Ippolito, Michela. 2006. Semantic composition and presupposition projection in subjunctive conditionals. Linguistics and Philosophy 29(6). 631-672. doi:10.1007/s10988-006-9006-2.

Lewis, David. 1973. Counterfactuals. Cambridge, MA: Harvard University Press. Ogihara, Toshiyuki. 2008. The semantics of -ta in Japanese subjunctive conditionals. Ms. University of Washington.

Palmer, Frank. 1986. Mood and modality. Cambridge: Cambridge University Press. Palmer, Frank. 2001. Mood and modality. Cambridge: Cambridge University Press 2nd edn.

Thomason, Richmond. 1984. Combinations of tense and modality. In Dov M. Gabbay \& Franz Guenthner (eds.), Handbook of philosophical logic: Extensions of classical logic, 135-165. Dordrecht: Reidel.

Naoko Komoto

Department of Linguistics

University of Washington

Box 354340, Seattle, WA 98195-4340

komotn@uw.edu 